\title{
Mechanical Thrombectomy for Perioperative Acute Ischemic Stroke: Two Noncardiac and Non-neurosurgical Case Reports and a Literature Review
}

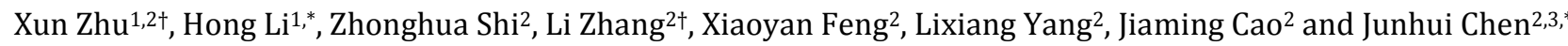 \\ 1 Department of Neurosurgery, The Second Hospital of Tianjin Medical University, Tianjin 300000, China \\ 2 Department of Neurosurgery, 904th Hospital of Joint Logistic Support Force of PLA, Wuxi Clinical College of Anhui Medical University, Wuxi, China \\ 3 Department of Neurosurgery, Renmin Hospital of Wuhan University, Wuhan, China. \\ $\dagger$ All the authors equally contributed to this study.
}

* Corresponding author: Junhui Chen, Department of Neurosurgery, Renmin Hospital of Wuhan University, No. 9 Zhangzhidong Road, Wuchang District, Wuhan, Hubei Province, China. Email: chenjunhui101@163.com; Hong Li, Department of Neurosurgery, The Second Hospital of Tianjin Medical University, Tianjin, China. Email: lihong3112@163.com

Received 2020 August 01; Revised 2020 September 01; Accepted 2020 September 22.

\section{Abstract}

Introduction: Perioperative acute ischemic strokes (PAISs) are rare; however, they have potentially catastrophic complications and outcomes. Endovascular therapy is the standard care in appropriately selected patients with acute ischemic stroke; nonetheless, there are no guidelines on the treatment of PAIS, and the majority of the patients receive conservative treatments. This study aimed to present two cases of mechanical thrombectomy (MT) for the treatment of PAIS.

Case Presentation: The first patient was a 43-year-old female who fell into a coma and had left limb dysfunction three $\mathrm{h}$ after undergoing hysteromyomectomy with a National Institute of Health Stroke Scale (NIHSS) score of 22. A right middle cerebral artery (M1) occlusion was detected on computed tomography angiography (CTA) leading to MT. The modified Rankin Scale (mRS) score was obtained at 1 three months after treatment. The second patient was a 59-year-old male who suddenly fell into a coma and had right limb dysfunction three $\mathrm{h}$ after undergoing a lung cancer operation with NIHSS score of 24. The CTA showed a left M1 occlusion leading to MT. The mRS score was 1 three months after treatment. Both patients were admitted to and treated in the Wuxi Clinical College of Anhui Medical University, Wuxi, China, in 2018.

Conclusion: The PAIS is a rare but serious complication after noncardiac surgery. In both cases, diagnosis and treatment were very difficult. Further evidence was provided to regard MT as a useful and safe method to treat PAIS.

Keywords: Postoperative complications, Stroke, Thrombectomy
\end{abstract}

\section{Introduction}

Perioperative acute ischemic stroke (PAIS) is a relatively rare and unwanted complication in patients that deserves attention because of its high rate of mortality and serious disability that can lead to prolonged hospital stay and high hospitalization expenses (1-3). Even though the incidence of PAIS is as high as $10 \%$ in patients who underwent high-risk cardiac or brain surgery (1), its incidence after noncardiac, non-neurologic, and nonmajor vascular surgery is low with previously reported ranges of approximately $0.1 \%$ to $1.9 \%$ depending on the associated risk factors $(2,4)$. Mashour (4) also reported that the incidence of perioperative strokes in both their derivation and validation cohorts was $0.1 \%$ for 523,059 noncardiac and non-neurologic patients in the American College of Surgeons National Surgical Quality Improvement Program database (4). Early diagnosis is very important; however, the vast majority of the perioperative strokes were ignored in the early stage. Unfortunately, many traditional forms of emergency advanced treatments for PAIS, such as thrombolysis and heparin administration, are not suitable for patients after surgery (5). Therefore, the outcomes after perioperative stroke are usually devastating due to the high mortality rate associated with PAIS (2, 5-7).

As many recent clinical trials have recommended, mechanical thrombectomy (MT) has become the standard treatment for acute ischemic stroke (AIS) with large vessel occlusions (8-12). Although PAISs have been deeply described and discussed in many large studies, the application of MT for PAIS has been rarely reported.

Mashour (4) reported that the absolute increase in the risk for mortality after stroke was $21 \%$ in the comorbidity-matched cohort and $24 \%$ in the derivation cohort. According to Premat (7), the mortality rate of perioperative strokes is as high as $33.3 \%$, while it is just $4.2 \%$ in the nonperioperative stroke group.

Since most patients were diagnosed with PAIS during or after operation within some hours, thrombolysis and heparin administration would increase the risk of bleeding. Even though thrombolysis had a good outcome, it is accompanied by a risk of surgical site bleeding in up to $25 \%$ of the patients including $8 \%$ of fatal bleeding in a previously conducted study (7). Accordingly, the majority of the patients with PAIS would not be able to continue previous related treatments and only choose conservative treatments, which may lead to a very poor survival rate among these patients $(7,13)$. The 
MT was consistently and safely able to achieve reperfusion in PAIS patients within a satisfactory amount of time and clinical outcome.

This study aimed to present two patients with PAIS in noncardiac and non-neurosurgical surgery who were admitted to The National Advanced Center of Stroke, Wuxi, China. Moreover, it focused mainly on the value of MT in managing PAIS.

\section{Case Presentation}

\subsection{Case one}

A 43-year-old female underwent hysteromyomectomy in a different hospital three hours earlier; however, she did not wake up after anesthesia and had left limb dysfunction (Table 1). Following that, the patient was transferred to our tertiary care center (Department of Neurosurgery, 904th Hospital of Joint Logistic Support Force of PLA, Wuxi Clinical College of Anhui Medical University, Wuxi, China) in June 2018. The time from the start of hysteromyomectomy to presentation in our emergency department was approximately $5 \mathrm{~h}$, and she was not considered a candidate for tissue plasminogen activator (tPA) treatment due to concomitant anticoagulation therapy from the large operation.

According to the neurologic examination results, the patient was comatose and had a Glasgow Coma Scale E2V2M5 (GCS) score of 9 and a National Institutes of Health Stroke Scale (NIHSS) score of 22. The head computed tomography (CT) showed an Alberta Stroke Program Early CT score (ASPECTS) of 12 , and computed tomography angiography (CTA) revealed a right middle cerebral artery (MCA)-M1 occlusion (Figure 1 A, B). A decision was made by the neurosurgeons, cerebrovascular doctors, and interventional cardiologists to proceed with an MT. The patient was immediately transferred to the digital subtraction angiography (1) operating room, managed with anesthesia care, and monitored.

Initially, an $8 \mathrm{~F}$ sheath was placed in the right common femoral artery with the Seldinger technique. Subsequently, an 8F Envoy sheath (Codman, Corids, USA) was placed into the right common carotid artery (CCA), and an angiogram confirmed the right MCA-M1 occlusion (Figure 1C). Following that, a 115$\mathrm{cm}$ 8F Navien guiding sheath (EV3, USA) was placed through the sheath with the same axle transfixion technique, and the head of the Navien guiding sheath was placed as close as possible to the site of the occlusion. In the next stage, Rebar 27 microcatheter (EV3, USA) was maneuvered across the MCA-M1 occlusion to the distal side of the MCA-M1 occlusion using microwires (Transcend 0.014, Boston Scientific, USA). The distal side of the MCA was kept open by microcatheters during the angiogram (Figure 1D). A Solitaire AB stent (EV3, USA) $(3 \times 20 \mathrm{~mm})$ was deployed across the thrombus and kept in place for 5 min (Figure 1E). The microcatheter and Solitaire AB device were then pulled back together; meanwhile, another assistant used the thrombus suction technique to avoid complications, such as thrombus disintegration, translocations, and thrombosis formation. Finally, angiography revealed TICI $2 b$ recanalization with reperfusion of the middle M2 trunk (Figure 1F). The total procedure lasted $86 \mathrm{~min}$. The follow-up CT acquired immediately after the operation revealed no hemorrhagic transformation or contrast media leakage (Figure 1G). Postoperative Transcranial Doppler sonography (TCD) monitoring showed the patency of the right MCA with vasospasms in the early period that were significantly relieved after one week (Figure $1 \mathrm{H}$ ). The patient was ultimately discharged from the hospice after 20 days and had the NIHSS and mRS scores of 2 and 1 at the 90-day follow-up, respectively.

\subsection{Case two}

A 59-year-old male suddenly fell into a coma and had right limb dysfunction for two h (Table 1). He underwent a small video-assisted thoracoscopic operation for lung cancer $10 \mathrm{~h}$ earlier. Subsequently, the patient was transferred to our tertiary care center (Department of Neurosurgery, 904th Hospital of Joint Logistic Support Force of PLA, Wuxi Clinical College of Anhui Medical University, Wuxi, China) in October 2018. The time from symptom onset to presentation in our emergency department was approximately 2.5 $h$, and he was not regarded as a candidate for tPA therapy due to concomitant anticoagulation therapy for the large operation. On the neurologic examination, he was comatose and had a GCS of 7 and an NIHSS score of 24. The head CT showed an ASPECTS of 11, and CTA revealed a left MCA-M1 occlusion (Figure $2 \mathrm{AB}$ ). A decision was made to proceed with an MT, and the patient was immediately sent to the DSA operating room, managed with anesthesia care, and monitored.

The patient received the same treatment as presented in case one, and an angiogram confirmed the right MCA-M1 occlusion (Figure 2C). The Solitaire $\mathrm{AB}$ device was also utilized for the thrombectomy. Finally, angiography revealed TICI 3 recanalization with reperfusion of the middle M2 trunk (Figure 2D).

\begin{tabular}{|c|c|c|c|c|c|c|c|c|c|c|c|c|c|}
\hline No. & Year & Age & Gender & Diagnosis & $\begin{array}{l}\text { Causative } \\
\text { procedure }\end{array}$ & Occlusion & NIHSS & $\begin{array}{c}\text { Time } \\
\text { (h) }\end{array}$ & GCS & ASPECTS & Solitaire & $\begin{array}{l}\text { mTICI } \\
\text { score }\end{array}$ & mRs \\
\hline 1 & 2018 & 43 & Female & $\begin{array}{l}\text { Cerebral } \\
\text { infarction }\end{array}$ & hysteromyomectomy & M1 & 22 & 5 & 9 & 12 & $\begin{array}{l}\text { Solitaire } \\
\mathrm{AB} \text { stent }\end{array}$ & $2 b$ & 1 \\
\hline 2 & 2018 & 59 & Male & $\begin{array}{c}\text { Cerebral } \\
\text { infarction }\end{array}$ & $\begin{array}{c}\text { lung cancer } \\
\text { operation }\end{array}$ & M1 & 24 & 2.5 & 7 & 11 & $\begin{array}{l}\text { Solitaire } \\
\mathrm{AB} \text { stent }\end{array}$ & 3 & 4 \\
\hline
\end{tabular}




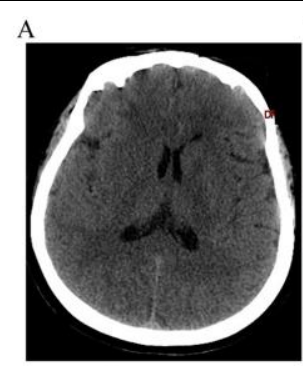

E
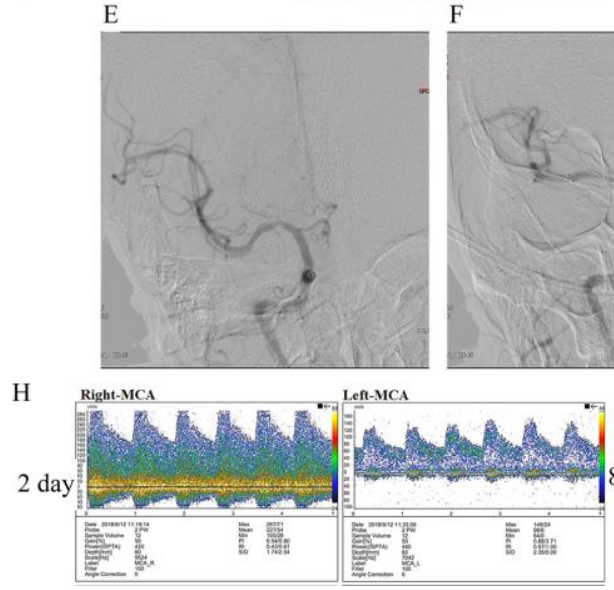

D
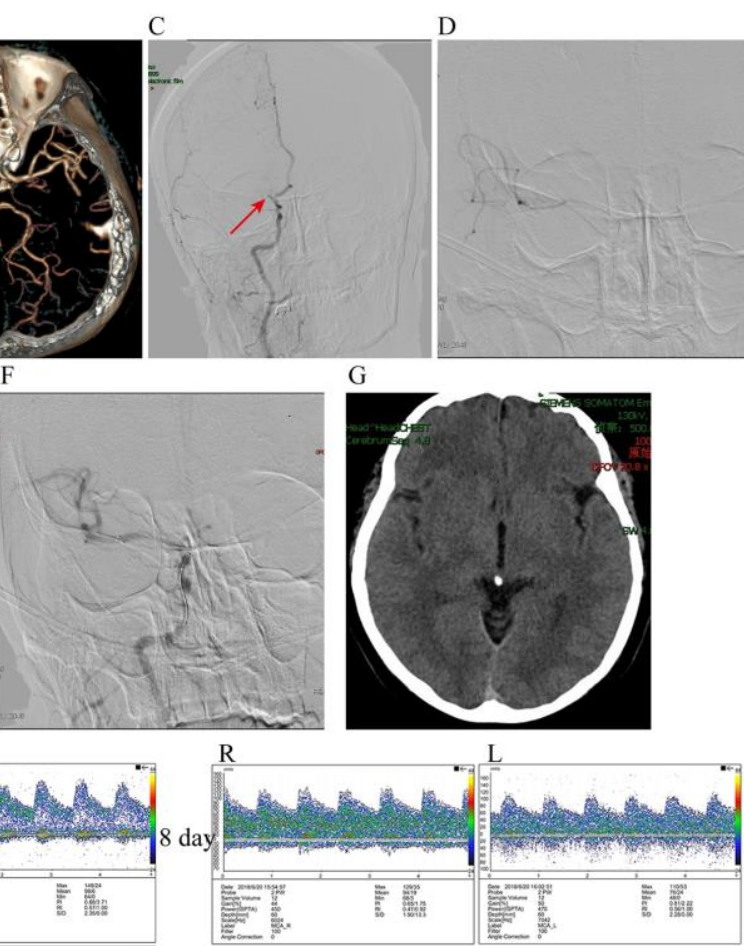

Figure 1. Case one, a 43-year-old female.

A. Head CT showing an ASPECTS of 12.

B. CTA showing a right MCA-M1 occlusion (Red arrow indicated).

C. DSA confirming the CTA results (Red arrow indicated).

$\mathrm{D}, \mathrm{E}$, and F. Mechanical thrombectomy process, and the last DSA revealing TICI $2 \mathrm{~b}$ recanalization with reperfusion of the middle M2 trunk (F). G. Postoperative CT showing no hemorrhagic transformations or contrast media leakage.

H. Postoperative TCD monitoring showing the patency of the right MCA.
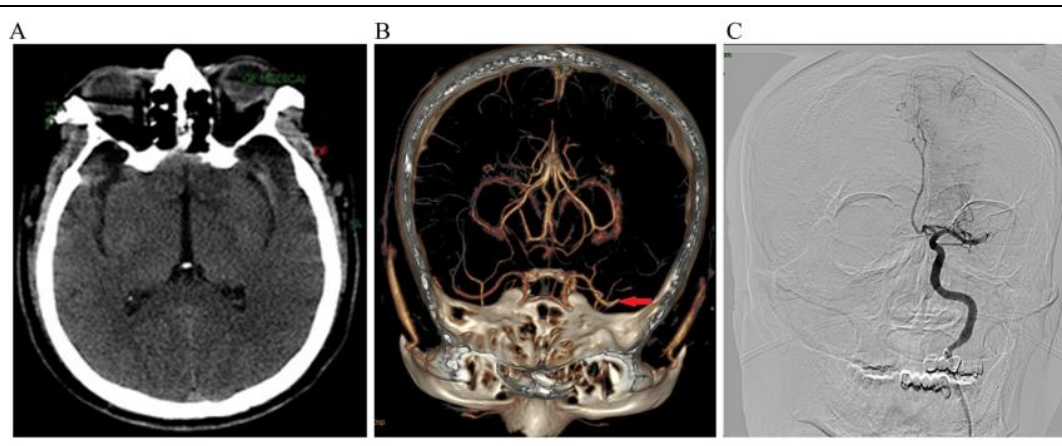

$\mathrm{D}$

E
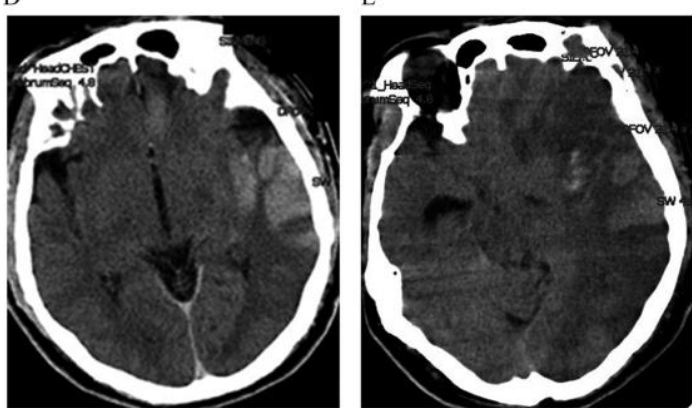

(

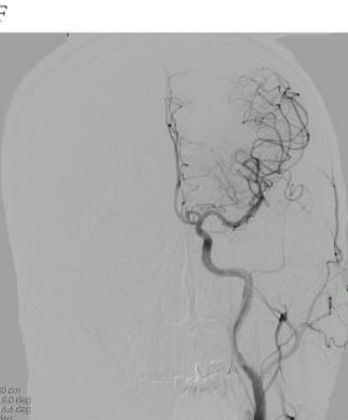

Figure 2. Case two: a 59-year-old male.

A. Head CT showing an ASPECTS of 11.

B. CTA revealing a left MCA-M1 occlusion (Red arrow indicated).

C. DSA confirming the right MCA-M1 occlusion.

D. Last DSA revealing TICI 3 recanalization with reperfusion of the middle M2 trunk. E. Postoperative CT revealing few hemorrhagic transformations and contrast media leakages.

F. CT revealing swelling in the left hemisphere (particularly in the left frontal, temporal and parietal lobes), pressure in the low left ventricle, and a large low-density midline shift to the right $12 \mathrm{~h}$ after surgery. 
A

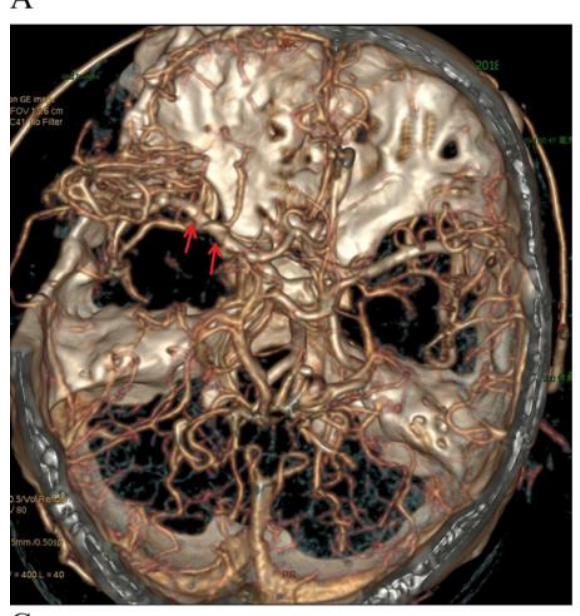

$\mathrm{C}$

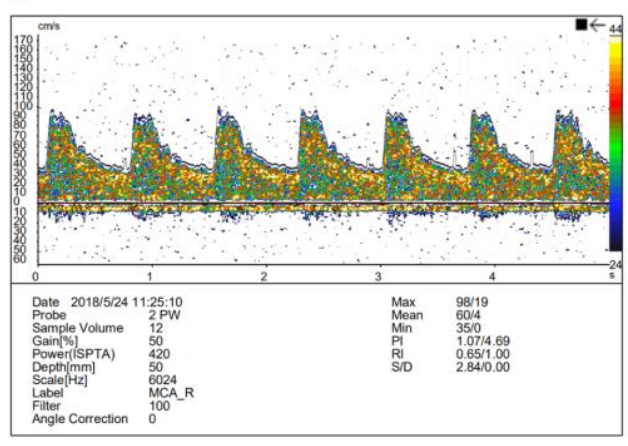

B

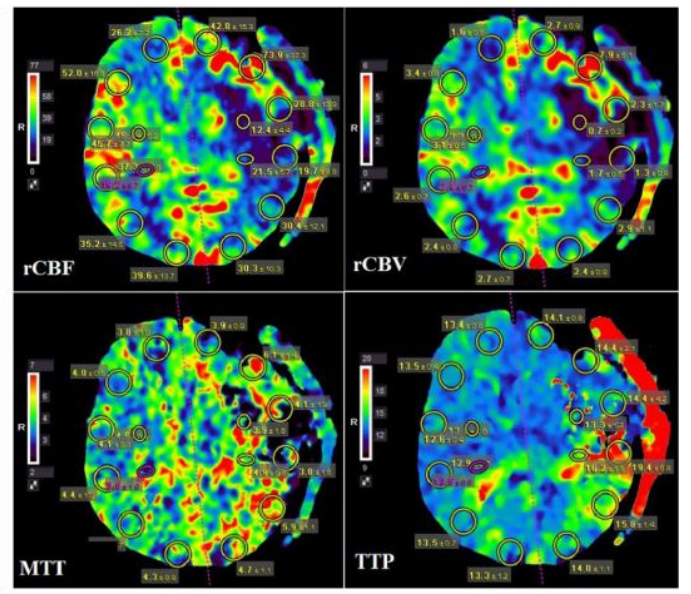

MTT

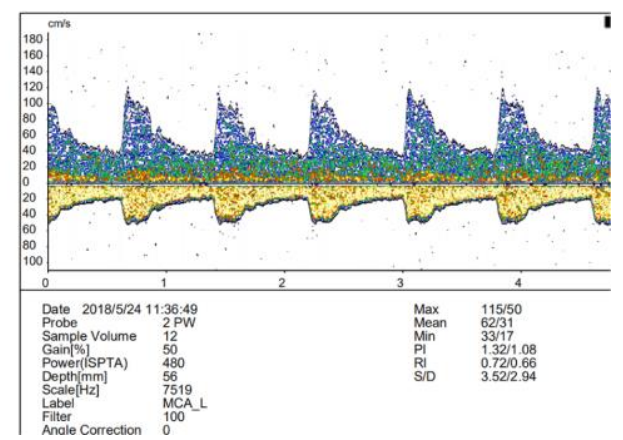

Figure 3.

A. Seven days after DC, CTA re-examination showing the patency of the left MCA (Red arrow indicated).

B. CTP scan revealing left hemisphere hypoperfusion and an infarct.

C. Postoperative TCD monitoring also confirming the patency of the left MCA; however, a relatively higher PI indicating higher intracranial pressure.

The total procedure time was $50 \mathrm{~min}$, and the follow-up CT was acquired immediately after the operation revealed few hemorrhagic transformations and contrast media leakage (Figure 2E). The GCS score of 7 decreased to 5 (12 h after surgery), and CT revealed swelling in the left hemisphere (particularly in the left frontal-temporal and parietal lobes), pressure in the low left ventricle, and a large low-density midline shift to the right (Figure 2F). The patient immediately underwent decompressive craniectomy (14) and was subsequently managed for seven days with mild hypothermia $\left(34-35^{\circ} \mathrm{C}\right)$ treatment. On the seventh day, the CTA re-examination showed patency of the left MCA (Figure 3A), and the CT perfusion (CTP) scan also revealed left hemisphere hypoperfusion and an infarct (Figure 3B). Postoperative TCD monitoring also confirmed patency of the left MCA; however, the relatively higher pulsatility index (PI) indicated higher intracranial pressure (Figure 3C). The patient was ultimately discharged from the hospice after 50 days and had an NIHSS and mRS scores of 13 and 4 at the 90-day follow-up, respectively.

\section{Discussion}

The PAIS is a relatively rare and unwanted complication for patients. The incidence of cerebral infarctions after general surgery is $0.2 \%$ (15). However, the incidence of cerebral infarctions after pulmonary lobectomy or segmentectomy has recently been reported to be as high as $4.5 \%$ (16). Kato (17) also reported 515 patients diagnosed with advanced or postoperative recurrent non-small cell lung cancer (NSCLC) at the Juntendo University Hospital, Tokyo, Japan, and $2.9 \%$ of the patients had cerebral infarctions. Furthermore, the overall survival time from the diagnosis of advanced NSCLC or postoperative recurrence to the analysis was significantly shorter in patients with cerebral infarction, compared to that in patients without cerebral infarctions. Since the majority of PAISs occur in non-neurologic or non-neurosurgical cases, this complication was also easy to misdiagnose, which delayed treatment. Therefore, diagnosis, prevention, and treatment of PAIS have become a very important topic for improving the outcomes. Through the review of the published literature, the treatment 


\begin{tabular}{|c|c|c|c|c|c|c|c|c|c|}
\hline First Author & Year & $\begin{array}{c}\text { Age } \\
\text { (year) }\end{array}$ & Gender & Diagnosis & $\begin{array}{c}\text { Causative } \\
\text { procedure }\end{array}$ & Occlusion & Treatment & $\begin{array}{c}\text { mTICI } \\
\text { score }\end{array}$ & $\begin{array}{c}\text { mRs at } 3 \\
\text { months }\end{array}$ \\
\hline $\begin{array}{l}\text { Thomas Nguyen } \\
\text { et al. } .^{22}\end{array}$ & 2019 & 5 & Male & $\begin{array}{l}\text { Cerebral } \\
\text { infarction }\end{array}$ & $\begin{array}{c}\text { spinal } \\
\text { operation }\end{array}$ & cerebellum & $\begin{array}{c}\text { conservativ } \\
\mathrm{e}\end{array}$ & no data & no data \\
\hline JM Ali et al. ${ }^{20}$ & 2019 & 84 & Male & $\begin{array}{l}\text { Cerebral } \\
\text { infarction }\end{array}$ & $\begin{array}{l}\text { pulmonary } \\
\text { lobectomy }\end{array}$ & M1 & MT & no data & 1 \\
\hline Zhu Binbin et al. ${ }^{18}$ & 2019 & 55 & male & $\begin{array}{c}\text { Cerebral } \\
\text { infarction }\end{array}$ & $\begin{array}{c}\text { upper } \\
\text { lobectomy }\end{array}$ & M1 & MT & no data & no data \\
\hline $\begin{array}{l}\text { Yusuke Morinaga } \\
\text { et al.19 }\end{array}$ & 2019 & $\begin{array}{l}71 \\
76\end{array}$ & $\begin{array}{l}\text { Male } \\
\text { male }\end{array}$ & $\begin{array}{l}\text { Cerebral } \\
\text { infarction }\end{array}$ & $\begin{array}{l}\text { Thoracic } \\
\text { Surgery }\end{array}$ & $\begin{array}{l}\text { M3 } \\
\text { M1 }\end{array}$ & MT & $\begin{array}{c}2 b \\
3\end{array}$ & $\begin{array}{l}3 \\
1\end{array}$ \\
\hline
\end{tabular}

methods of PAIS were summarized in Table 2 . However, no studies have yet investigated long-term outcomes and detailed assessments before and after treatment. In addition, the majority of the patients come from pulmonary lobectomy, and the clinical information was not sufficient in this regard.

In the present study, the first patient underwent a hysteromyomectomy, did not wake up after anesthesia, and had left limb dysfunction. The CTA revealed a right MCA-M1 occlusion. On the other hand, the second patient underwent a small videoassisted thoracoscopic operation for lung cancer, suddenly fell into a coma, and had right limb dysfunction for two h. The CTA revealed a left MCAM1 occlusion. The diagnoses of both patients were confirmed by CTA promptly, and MT was also performed on time; accordingly, they both had good outcomes. It is worth mentioning that both of these PAIS cases occurred after surgery.

Mechanisms of the PAIS development in patients, especially in those with tumors, may include the stasis of blood flow in the stump of the left upper pulmonary vein after lung cancer operations, which allows a thrombus to develop easily (18). That is why the incidence of AIS was higher in patients who underwent lung cancer operations, compared to other patients. Furthermore, tumors and tumor emboli, especially myxomas, can directly cause AISs. A previously conducted study reported that extensive and rapidly growing neoplasms (lung cancer) generate large emboli. Lung cancer emboli and other systemic metastatic tumors can frequently affect cerebral circulation (18-20). Coagulation disorders are the most important mechanisms for PAIS development. Primarily, cancer is known to have severe complications related to coagulation disorders, such as disseminated intravascular coagulation (21). Secondly, large operations and stress reactions can similarly lead to coagulation disorders. Other risk factors may be closely related to the development of PAIS, such as type 2 diabetes, high plasma concentrations of C-reactive protein and inflammation-sensitive plasma proteins, as well as genetic mutations associated with stroke (22-24).

The PAISs are very difficult to treat and have poor outcomes; accordingly, the key is to prevent the occurrence of PAISs. Subcutaneous heparin injections are probably insufficient, and early postoperative systemic heparinization treatment should be considered. Early postoperative fibrinolytic or/and anticoagulation therapy is especially important and useful for high-risk patients and those who underwent lung cancer operations $(16,25)$. The presence of perioperative risk factors should be fully evaluated, and the PAIS-related risk factors should especially be paid attention to. The patients should undergo accurate neurologic and neuropsychological examinations after surgery or in the recovery room. Once coma, dyskinesia, or facial palsy occur, head CTA and treatment should be performed promptly.

The PAIS is very difficult to manage, especially in patients who underwent operations. Very few previous studies or case reports were available to help guide the management of these patients. Most patients receive heparin treatment or are transferred to other hospitals or departments to receive intravascular therapy (25); however, the outcome is poor if a large cerebrovascular occlusion is noted. Traditional treatments, such as thrombolysis and heparin administration, are not suitable for patients after surgery. Therefore, MT may be the most appropriate choice for these patients. In the present study, both patients underwent MT on time, and the postoperative angiography and TCD monitoring revealed cerebrovascular TICI $2 \mathrm{~b}$ recanalization with reperfusion. It should be mentioned that both patients had good outcomes after a long follow-up period.

Premat (7) analyzed perioperative strokes in a case-control study and indicated that MT was a quick and safe method for opening occluded cerebrovascular vessels. Moreover, the results showed essential reperfusion in AIS patients in the postoperative period. Even though MT may help improve the outcomes of AIS patients as part of the global management strategy, time is directly linked to brain tissue preservation that can determine which patients can undergo this procedure.

Regarding the strength of the current study, one can name the confirmation of the effectiveness of MT to treat PAIS that has already been highlighted in other studies representing a great opportunity for patients. On the other hand, the retrospective nature of this study that was conducted in a singleinstitution with a small number of cases can be regarded as a limitation associated with our study. 
Therefore, further investigations with larger series and randomized controlled trials are required to confirm the potential benefits of MT for PAIS.

The PAIS is a relatively rare condition that is challenging to manage and has poor outcomes. Since "Time is brain", an accurate early diagnosis, full assessment, and optimized periprocedural management strategy in highly skilled centers are important once this kind of stroke appears. Furthermore, timely CTA re-examinations should be performed in the perioperative period. The MT has become a global management strategy for large cerebrovascular occlusions.

\section{Acknowledgements}

The authors would like to thank all the participants in the study.

\section{Footnotes}

Authors' Contribution: Xun Zhu and Junhui Chen conceived the study and contributed to designing the study and drafting the manuscript. Hong $\mathrm{Li}$, Zhonghua Shi, and Li Zhang conducted the study protocol. Xiaoyan Feng, Lixiang Yang, and Jiaming Cao advised on the method of massage therapy, and Li Zhang advised on data collection. Xun Zhu, Hong Li, and Junhui Chen revised and approved the manuscript. Li Zhang and Xiaoyan Feng approved radiological material support.

Conflict of Interests: None.

Ethical Approval: All procedures performed in studies involving human participants were in accordance with the ethical standards of the institutional and/or national research committee and with the 1964 Helsinki Declaration and its later amendments or comparable ethical standards. This observational prospective study was conducted in the department of neurosurgery at Wuxi Medical College of Anhui Medical University, Chinese PLA joint services of 904th Hospital (10lth Hospital of PLA). The protocol of the present study was approved by the Ethics Committee of Chinese PLA joint services of 904th Hospital (YXLL-2018-010).

Funding/Support: This study was supported by the Nanjing military area research fund major project (Grant/Award Number: 15DX003); Youth project of Wuxi Natural Science Foundation (Grant/Award Number: Q201611); Wuxi science and technology development fund project (Grant/Award Number: WX18IIAN041).

Informed consent: Informed consent was obtained from all individual participants included in the study.

\section{References}

1. Selim M. Perioperative stroke. N Engl J Med. 2007;356(7):70613. doi: 10.1056/NEJMra062668. [PubMed: 17301301].

2. Bateman BT, Schumacher HC, Wang S, Shaefi S, Berman MF.
Perioperative acute ischemic stroke in noncardiac and nonvascular surgery incidence, risk factors, and outcomes. Anesthesiology. 2009;110(2):231-8. doi: 10.1097/ALN.0b013e 318194b5ff. [PubMed: 19194149].

3. Chang R, Reddy RP, Sudadi S, Balzer J, Crammond DJ, Anetakis $\mathrm{K}$, et al. Diagnostic accuracy of various EEG changes during carotid endarterectomy to detect 30-day perioperative stroke: a systematic review. Clin Neurophysiol. 2020;131(7):1508-16. doi: 10.1016/j.clinph.2020.03.037. [PubMed: 32403063].

4. Mashour GA, Shanks AM, Kheterpal S. Perioperative stroke and associated mortality after noncardiac, nonneurologic surgery. Anesthesiology. 2011;114(6):1289-96. doi: 10.1097/ALN. 0b013e318216e7f4. [PubMed: 21478735].

5. Ng JL, Chan MT, Gelb AW. Perioperative stroke in noncardiac, nonneurosurgical surgery. Anesthesiology. 2011;115(4):87990. doi: 10.1097/ALN.0b013e31822e9499. [PubMed: 21862923].

6. El-Saed A, Kuller LH, Newman AB, Lopez O, Costantino J, McTigue K, et al. Geographic variations in stroke incidence and mortality among older populations in four US communities. Stroke. 2006;37(8):1975-9. doi: 10.1161/01.Str.0000231453. 98473.67. [PubMed: 16794205].

7. Premat K, Clovet O, Polara GF, Shotar E, Bartolini B, Yger M, et al. Mechanical thrombectomy in perioperative strokes a casecontrol study. Stroke. 2017;48(11):3149-51. doi: 10.1161/ strokeaha.117.018033. [PubMed: 29018130].

8. Goyal M, Demchuk AM, Menon BK, Eesa M, Rempel JL, Thornton J, et al. Randomized assessment of rapid endovascular treatment of ischemic stroke. $N$ Engl J Med. 2015;372(11):1019-30. doi: 10.1056/NEJMoa1414905. [PubMed: 25671798].

9. Saver JL, Goyal M, Bonafe A, Diener HC, Levy EI, Pereira VM, et al. Stent-retriever thrombectomy after intravenous t-PA vs. tPA alone in stroke. $N$ Engl J Med. 2015;372(24):2285-95. doi: 10.1056/NEJMoa1415061. [PubMed: 25882376].

10. Jovin TG, Chamorro A, Cobo E, de Miquel MA, Molina CA, Rovira A, et al. Thrombectomy within 8 hours after symptom onset in ischemic stroke. $N$ Engl J Med. 2015;372(24):2296-306. doi: 10.1056/NEJMoa1503780. [PubMed: 25882510].

11. Campbell BC, Mitchell PJ, Kleinig TJ, Dewey HM, Churilov L, Yassi N, et al. Endovascular therapy for ischemic stroke with perfusion-imaging selection. $N$ Engl J Med. 2015;372(11): 1009-18. doi: 10.1056/NEJMoa1414792. [PubMed: 25671797].

12. Bracard S, Ducrocq X, Mas JL, Soudant M, Oppenheim C, Moulin $\mathrm{T}$, et al. Mechanical thrombectomy after intravenous alteplase versus alteplase alone after stroke (2): a randomised controlled trial. Lancet Neurol. 2016;15(11):1138-47. doi: 10.1016/s1474-4422(16)30177-6. [PubMed: 27567239].

13. Bell DS, Goncalves E. Stroke in the patient with diabetes (part 1)- Epidemiology, etiology, therapy and prognosis. Diabetes Res Clin Pract. 2020;164:108193. doi: 10.1016/j.diabres.2020. 108193. [PubMed: 32442554].

14. Willis EF, MacDonald KPA, Nguyen QH, Garrido AL, Gillespie ER, Harley SBR, et al. Repopulating microglia promote brain repair in an IL-6-dependent manner. Cell. 2020;180(5):83346.e16. doi: 10.1016/j.cell.2020.02.013. [PubMed: 32142677].

15. Wolf PA. Fifty years at Framingham: contributions to stroke epidemiology. Adv Neurol. 2003;92:165-72. [PubMed: 12760179].

16. Matsumoto K, Sato S, Okumura M, Niwa H, Hida $Y$, Kaga K, et al. Left upper lobectomy is a risk factor for cerebral infarction after pulmonary resection: a multicentre, retrospective, casecontrol study in Japan. Surg Today. 2020;In Press. doi: 10.1007/s00595-020-02032-4. [PubMed: 32556550].

17. Kato M, Shukuya T, Mori K, Kanemaru R, Honma Y, Nanjo Y, et al. Cerebral infarction in advanced non-small cell lung cancer: a case control study. BMC Cancer. 2016;16:203. doi: 10.1186/s12885-016-2233-1. [PubMed: 26964872].

18. Ohtaka K, Hida Y, Kaga K, Kato T, Muto J, Nakada-Kubota R, et al. Thrombosis in the pulmonary vein stump after left upper lobectomy as a possible cause of cerebral infarction. Ann Thorac Surg. 2013;95(6):1924-8. doi: 10.1016/j.athoracsur. 2013.03.005. [PubMed: 23622699].

19. Oneill BP, Dinapoli RP, Okazaki H. Cerebral infarction as a result of tumor emboli. Cancer. 1987;60(1):90-5. doi: 
10.1002/1097-0142(19870701)60:1<90::Aidcncr2820600116>3.0.Co;2-c. [PubMed: 3581035].

20. Park JH, Seo HS, Park SK, Suh J, Kim DH, Cho YH, et al. Spontaneous systemic tumor embolism caused by tumor invasion of pulmonary vein in a patient with advanced lung cancer. J Cardiovasc Ultrasound. 2010;18(4):148-50. doi: 10.4250/jcu.2010.18.4.148. [PubMed: 21253365].

21. Hiatt BK, Lentz SR. Prothrombotic states that predispose to stroke. Curr Treat Options Neurol. 2002;4(6):417-25. doi: 10.1007/s11940-002-0009-1. [PubMed: 12354368].

22. Kothari V, Stevens RJ, Adler AI, Stratton IM, Manley SE, Neil HA, et al. UKPDS 60 - risk of stroke in type 2 diabetes estimated by the UK prospective diabetes study risk engine. Stroke. 2002;33(7):1776-81. doi: 10.1161/01.Str.0000020091.07144.C7.
[PubMed: 12105351].

23. Rost NS, Wolf PA, Kase CS, Kelly-Hayes M, Silbershatz H, Massaro JM, et al. Plasma concentration of C-reactive protein and risk of ischemic stroke and transient ischemic attack the framingham study. Stroke. 2001;32(11):2575-9. doi: 10.1161/hs1101.098151. [PubMed: 11692019].

24. Morrison AC, Ballantyne CM, Bray M, Chambless LE, Sharrett AR, Boerwinkle E. LPL polymorphism predicts stroke risk in men. Genet Epidemiol. 2002;22(3):233-42. doi: 10.1002/ gepi.0191. [PubMed: 11921083].

25. Kitajima A, Otsuka Y, Lefor AK, Sanui M. Acute cerebral infarction in a patient with an epidural catheter after left upper lobectomy: a case report. BMC Anesthesiol. 2019;19(1):27. doi: 10.1186/s12871-019-0695-9. [PubMed: 30797239]. 